\title{
Urban infrastructures and physical hazards: a challenge for planning
}

\author{
M. Tira, M. Tiboni, B. Badiani \& C. Confortini \\ Department of Civil Engineering, Architecture, \\ Land and Environment University of Brescia, Italy
}

\begin{abstract}
Physical hazards and their interrelation with the urban habitat are likely to be more and more important within the process of urban and regional planning [1]. Traditionally, and in Italy as well, Governments have attempted to tackle disasters after they have occurred, by means of measures aimed at mitigating the effects that future events might have on society. But such measures have proved to be inadequate for bringing risk levels down to socially acceptable levels. During the last decades Italian cities have often grown up without concern for the problems aroused by physical hazards and underestimating the consequences of land use transformations that may cause further risks, such as an increase of flooding hazard, for example. The demand for an environmentally sustainable urban growth forces decision makers to set up a methodology of territorial analysis, where space is considered as a complex system and the quality and quantity of relations among the elements of such systems as one of the prominent index of the damage caused by an event. So that vulnerability of human settlements (built-up areas and infrastructures) become (or rather should be) structural contents of plans. This paper presents a methodological approach to the analysis of regional infrastructure vulnerability and consequent options for planning and land use management. The effects of a disaster and the related evolution of the system are foreseen in order to reduce impacts and damage and to set up a quick restoring. An interactive model has been used for the analysis of relations, as tested in a study case in the North of Italy (Confortini and Tira, 2005). The use of the model allows planners to check scenarios and to better suit the infrastructure facilities.
\end{abstract}

Keywords: risk analysis, vulnerability index of urban infrastructures, level of service of urban infrastructures. 


\section{The risk concept}

The idea of planning a safer city, where people feel safe as regards the possibility of natural events, has been rife for some time and has occupied the minds of town-planners and designers, but maybe not enough the agenda of decision makers.

One of the prime objectives of town planning ought therefore to be the raising of safety levels of people who live and move about in town and cities, with the crucial contribution of specific competencies and the participation of stakeholders.

From a scientific viewpoint, experts agree that risks stem from two sources the hazard, meaning the likelihood of the event occurring $(\mathrm{P})$, and the losses such event could cause (L):

$$
\mathrm{R}=\mathrm{P} \times \mathrm{L}
$$

For a successful analysis however, in order to take into account geographic differences and population density, the concepts of vulnerability and exposure must be introduced. The generic loss, or damage rate concept is therefore replaced by:

- Vulnerability (V), or the propensity to suffer damage as a result of an event. More specifically, the planner's attention is directed towards the vulnerability of:

- buildings;

- infrastructures;

- district systems

- $\quad$ Exposure (E), meant as quantity and value of assets (human beings and material assets) in the area affected by the event.

Hazard, vulnerability and exposure depend on the intensity (I) of the event and type (T) of elements subject to risk. The risk function thus takes on the complete form [6]:

$$
\mathrm{R}=\mathrm{f}(\mathrm{I}, \mathrm{P}, \mathrm{V}, \mathrm{T}, \mathrm{E})
$$

Land use planning, both at regional and local scale, can most definitely affect vulnerability and exposure, while with respect to hazard, this strongly depends on the type of event [1].

\section{The vulnerability of infrastructures}

With the idea of safeguarding human lives and material assets in a natural disaster context, the scientific community is most definitely duty bound to focus on the vulnerability of infrastructures, after extensive studies concerning the vulnerability of buildings [7]. The structure aspect has quite rightly always been considered a priority factor because the largest number of disaster victims is generally caused by falling buildings. Other crucial aspects do exist however, 
above all for the feasible management of the emergency immediately after the catastrophe and for quick post-emergency rebuilding.

If we consider the network infrastructures (lifelines) we see that these are highly vulnerable to earthquakes, floods, landslides, political conflicts, terrorism and other disasters of natural and social origin. Were these to be damaged, this would produce indirect effects, with the result of a heavier impact in terms of human life and economic losses. The study of their vulnerability is thus becoming increasingly more urgent and important. The extensive presence of such networks throughout the area to ensure the different kinds of services are provided on a national, regional and local scale makes the issue relating to the damage they could suffer as a result of natural calamities of paramount interest.

The very fact that these networks are so numerous and widespread, as well as being linked together, underscores the problem of the need to carry out what looks like being a very complex study.

But the significant thing is not only that the network no longer provides a service. Often it is the breakdown of the infrastructure that causes injury to people and damage to things, and what is more, the fact that the networks are close together often causes a sort of domino effect as regards the damage produced, which makes danger scenarios even more complex and articulated.

\section{Work objective}

The objective of this work is to present a new methodology to help area prevention and planning bodies to take decisions [5].

By way of experiment, the study centres on just one infrastructure, the road system, in an area covering eight Municipalities in the Province of Brescia, in northern Italy.

A number of road link interruptions have been simulated with risk scenarios in the Municipal and Inter-Municipal Emergency Plans, with the use of a traffic model for calculating changes in traffic flows along the network according to the shortest (in time) route criteria.

Subsequently, the results obtained were used to create three vulnerability indexes. To provide a classification of the vulnerability of the different network sections, so as to highlight the points most sensitive to changes in the disaster events expected for the area being examined, is in fact very definitely a step in the right direction as regards forecasting and prevention, especially if focus extends beyond local boundaries, as major repercussions on other parts of the district often escape notice.

\section{Simulation of risk scenarios}

The study area is that of the eight municipalities of the piedmont area of Basso Sebino-Franciacorta in the Province of Brescia-Italy.

The study focuses mainly on provincial roads, the heaviest traffic loaded, with their various tunnels - potential critical elements in an emergency context. 
The risks affecting the area being examined consist of flooding caused by a number of streams and modest gravitative phenomena.

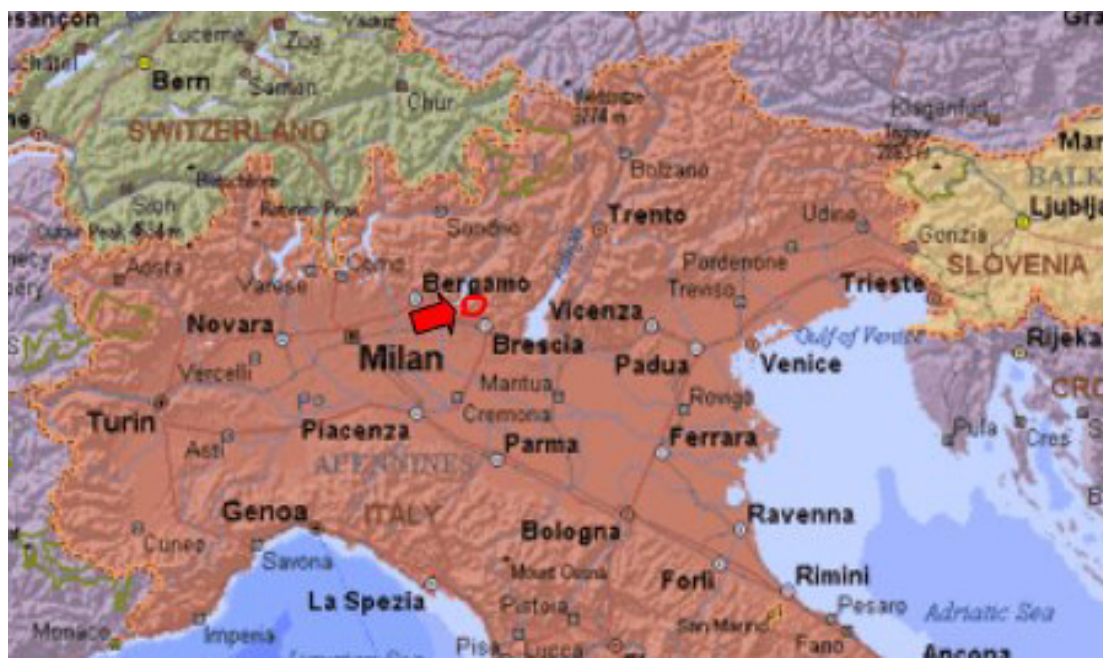

Figure 1: The study area, in northern Italy, south of Lake Iseo.

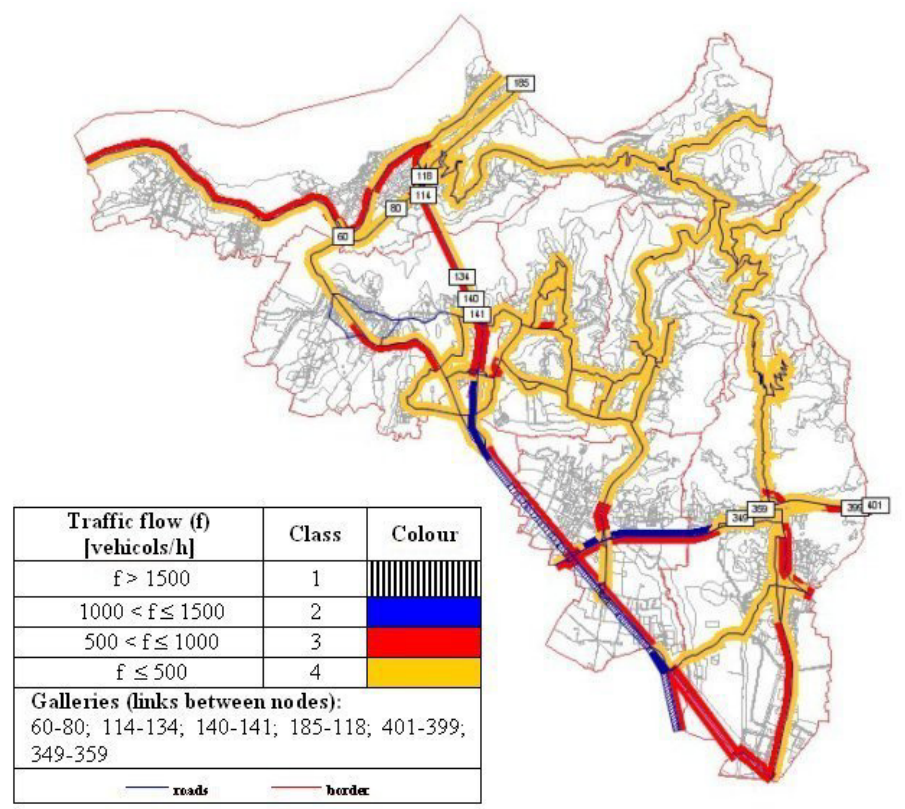

Figure 2: The eight municipalities of the area being examined and the distribution of the traffic flows in normal conditions, on the main roads. 
The first step is to assess traffic distribution in normal conditions, meaning without any traffic flow interruptions and restrictions. The decision was taken to analyse morning traffic between 7.30 am and $8.30 \mathrm{am}$, considered to be the rush hour. An analysis of the flows associated with each link showed that a hierarchy can be established, according to the amount of load, which is a sort of risk exposure index: the higher the load on a link, the higher its level of exposure. The links were grouped in 4 classes, according to flow.

Two simulations were then made by interrupting a number of road sections following local disaster events indicated in the Municipal Emergency Plans, for the purpose of analysing the new expectable traffic flow distribution, by means of the model. The aim in fact is to organise elements often investigated separately, such as danger levels, exposure and the physical and functional vulnerability of the territorial elements of the area being examined

The importance of simulating an articulated scenario is in fact related to the importance - for whosoever wants to elaborate risk-reducing planning, programming and intervention strategies - of being able to forecast expected damage and restrict its extension, but above all to forecast possible domino effects throughout a wider area, and identify the areas and infrastructures that could be hit.

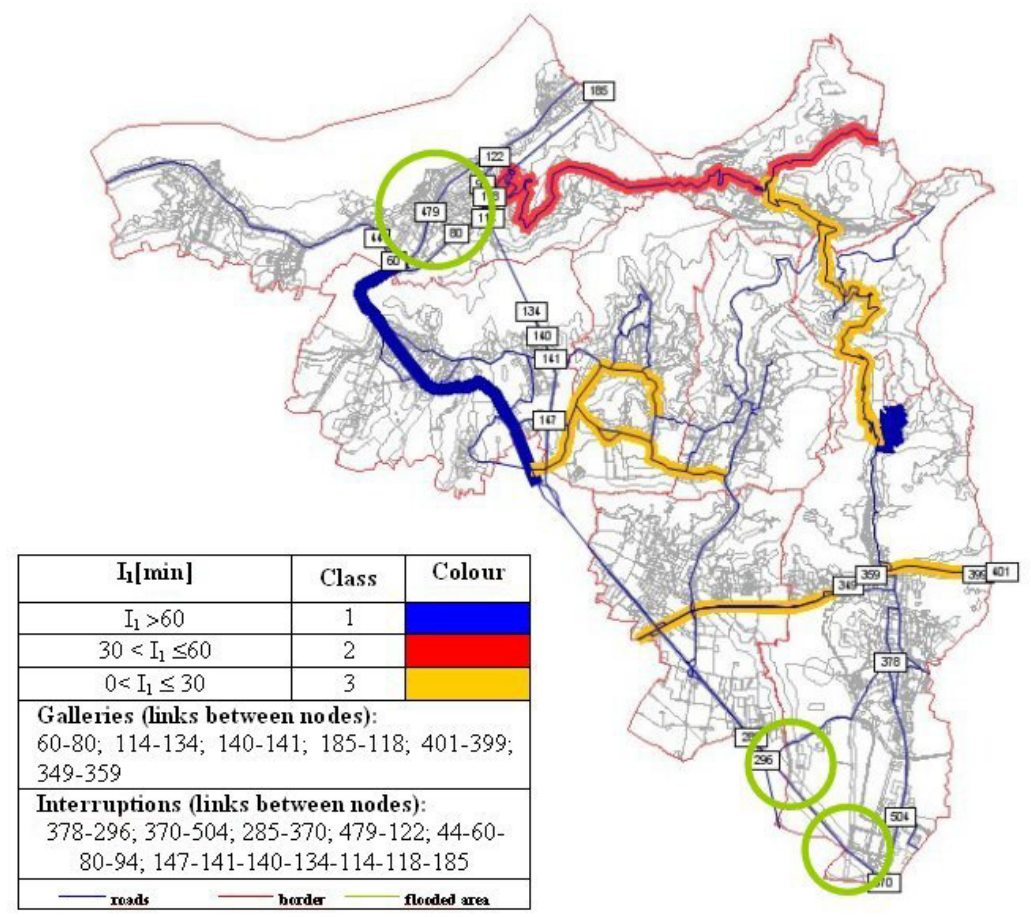

Figure 3: Distribution of the values of index $\mathrm{I}_{1}$, in simulation 1. This indicates the disturbance difference in terms of time according to the type of disaster event on the various network components. 


\section{Vulnerability indexes}

To compare the responses of the network in terms of vulnerability to link interruptions, three indexes were introduced, on the basis of those proposed by Tiboni and Tira [3]. The indexes $\mathrm{I}_{1}$ and $\mathrm{I}_{2}$ were applied both at network level and at the level of each individual road, while index $\mathrm{I}_{3}$ was applied along different sections of the three major roads. The index values were grouped together into four vulnerability classes.

\subsection{Index $\mathbf{I}_{1}$}

The interruption of a link can change to a greater or lesser extent the amount of time it takes to cover a distance between two nodes and the higher the flow on the links before the event that changed the mobility system, the greater the negative effect on the system.

Index $\mathrm{I}_{1}$ indicates by how many minutes on average each person moving along the road system is penalised due to link interruption.

This assessment was also made for the single roads. In this case, it expresses the average disturbance suffered, in terms of time, by the driver covering the road under examination from one end to another.

Such assessment enables the planner to identify the disaster events able to create serious disturbances on which to intervene in advance, and which are to be considered as negligible.

where:

$$
I_{1}=\frac{\sum_{i, j=1}^{N} \Delta t_{i j} \cdot f_{i j}}{\frac{\sum_{i, j=1}^{N} f_{i j}}{n_{\text {directions }}}} \text { [min] }
$$

$\Delta \mathrm{t}_{\mathrm{ij}}=$ variation in saturation travel time between nodes $\mathrm{i}$ and $\mathrm{j}$;

$\mathrm{f}_{\mathrm{ij}}=$ flow between $\mathrm{i}$ and $\mathrm{j}$ before link interruption;

$\mathrm{n}_{\text {directions }}=$ is the total number of the directions, not the links. If a link is one-way, the number of directions to be considered will be one only. If on the other hand it is two-way, the directions to be considered will be two.

\subsection{Index $\mathbf{I}_{2}$}

$\mathrm{I}_{2}$ represents an average change in flow on the links: the higher the value, the more the system moves away from the "balanced" condition represented by the current situation. The higher the index then, the greater the change compared to the network balance following the interruption of the specific link. This change is considered as "worsening", with reference to a positive increase in load on the links, ignoring the negative flow changes which correspond on the other hand to the lightening of the load. The reason for this is that, as regards emergency prevention and management, it is important to know what will change for the worse and what will become a potential problem. 
where:

$$
I_{2}=\sqrt{\frac{\sum_{i, j=1}^{N} \Delta f_{i j}^{2}}{n_{\text {directions }}}} \quad[\text { flow/direction }]
$$

$\Delta \mathrm{f}_{\mathrm{ij}}=$ change of positive flow (if it is negative it is not considered) on the link in the direction between nodes $\mathrm{i}$ and $\mathrm{j}$ occurring following the interruption of a network link;

$\mathrm{n}_{\text {directions }}=$ is the total number of the directions, not the links. If a link is one-way, the number of directions to be considered will be one only. If on the other hand it is two-way, the directions to be considered will be two.

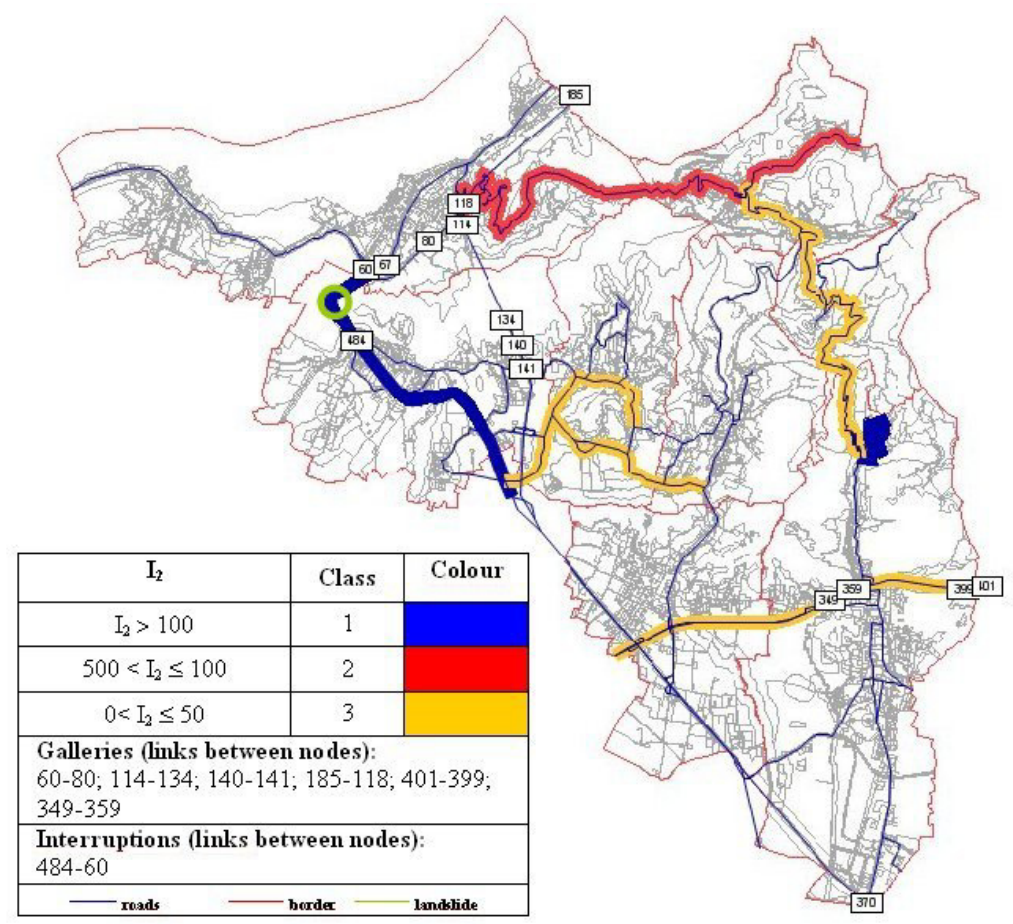

Figure 4: Distribution of the values of index $I_{2}$, in simulation 1. This indicates the difference in negative impact of the disaster event on the various network components.

\subsection{Index $I_{3}$}

The third index identifies what are called "bottlenecks" on main roads. These are sections with traffic jams that cannot be eliminated by deviating the traffic along alternative routes. The index has been created considering the road sections between two slip roads or major access roads and along which, for the model, the flow is therefore constant. 
The higher the value of index $\mathrm{I}_{3}$, the higher the propensity of the road section to form "bottlenecks" following the interruption of a specific network link. This consists of an independent part of the scenario relating to the characteristics of the road section (length of tunnels, presence of exits, number of lanes, type of carriageway, length of raised sections) and of another dependent on the scenario, meaning variation in traffic flow calculated by means of the model.

$$
I_{3}=\frac{L \cdot \Delta f}{a \cdot b \cdot c \cdot d \cdot e \cdot 100}
$$

where:

$\mathrm{L}=$ length of considered road section in kilometres; $\Delta \mathrm{f}=$ flow variation along the road section being examined due to interruption of a part of the network. This is considered by direction and not by road section; $a, b, c, d, e=$ indexes tied to the characteristics of the road section. Different degrees of importance have been attributed to the different index characteristics. These range between 0 (excluded) and 1, equal to 1 when the best conditions exist for traffic flow.

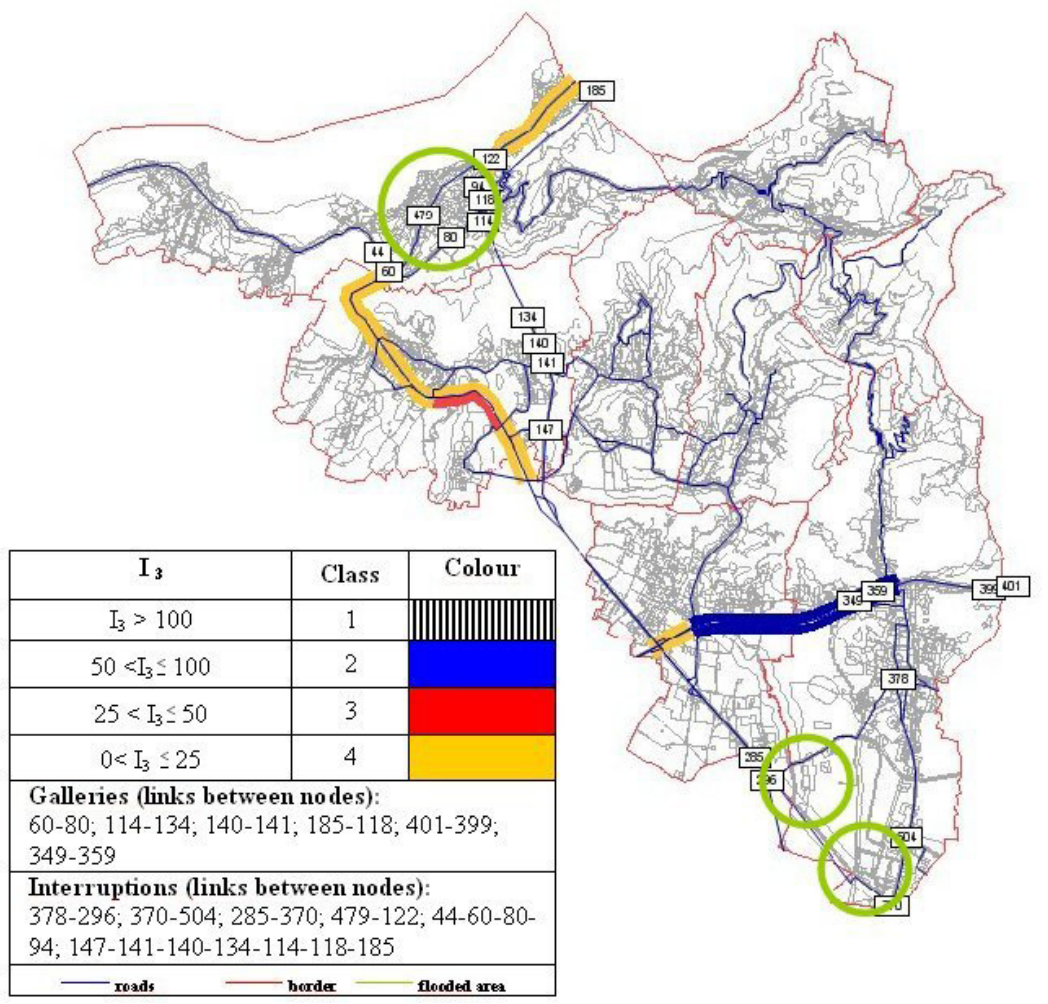

Figure 5: Example of graphic representation of the results obtained for index $\mathrm{I}_{3}$, showing the road sections, split up into classes, where likelihood exists of the formation of bottlenecks following the interruption of a number of road sections due to floods. The flooded areas are circled in green. 


\section{Conclusions}

A first application, restricted to two case study scenarios, has made it possible to successfully check the use of the devised method, a tool able to provide precious information for drawing up emergency plans and mitigating damage in a more general sense.

The proposed work can also be extended to other area contexts as it focuses attention on characteristics common to all road networks. The calculated vulnerability indexes are in fact mainly created through traffic flows, to which must be added, for index $\mathrm{I}_{3}$, the characteristics of the road sections.

The model can therefore most definitely be extended to include several areas and a larger surrounding area, in order to grasp the repercussions of an event on a bigger geographic scale and determine, with greater precision, the complex interactions between the network elements.

Along with an extension of the analysed area, the model can be upgraded through a more detailed definition of the network parameters, on a local scale. This would lead to a refinement of the application, depending on the level of detail and precision required.

It is also believed that the proposed method can provide an idea for the formulation of vulnerability indexes for other lifelines, naturally after adapting the parameters to the new characteristics of the object under examination and to the requirements of the bodies entrusted with planning for the prevention and management of emergencies.

\section{References}

[1] Tira, M., Pianificare la Città Sicura, Edizioni Librerie Dedalo, 1997.

[2] Imbesi, G., Conoscenza/ Azione: per la Prevenzione, un Laboratorio Ambientale. Proc. Of the International Conference Piano e progetto nelle aree a rischio sismico, Cangemi, Roma, 1994

[3] Tiboni, M.\& Tira, M., Pianificazione delle Aree a Rischio Fisico: vulnerabilità del sistema viabilistico ed impatto dell'innovazione tecnologica, Department of Civil Engineering, Architecture, Land and Environment, University of Brescia, 1995.

[4] Tiboni, M., La Prospettiva dello Sviluppo Sostenibile - Pianificare per la Sicurezza la Città e il Territorio, Sintesi Editrice Brescia, 2002.

[5] Confortini, C. \& Tira, M., Infrastrutture Urbane e Territoriali e Protezione Civile, Department of Civil Engineering, Architecture, Land and Environment, University of Brescia, 2005.

[6] Varnes, DJ. \& Commission on Landslide and Other Mass Movement IAEG, The Principles and practise of landslide hazard zonation, the UNESCO Press, 1984.

[7] Regione Lombardia e Consiglio Nazionale Ricerche - CNR, Determinazione del rischio sismico a fini urbanistici in Lombardia, 1996. 